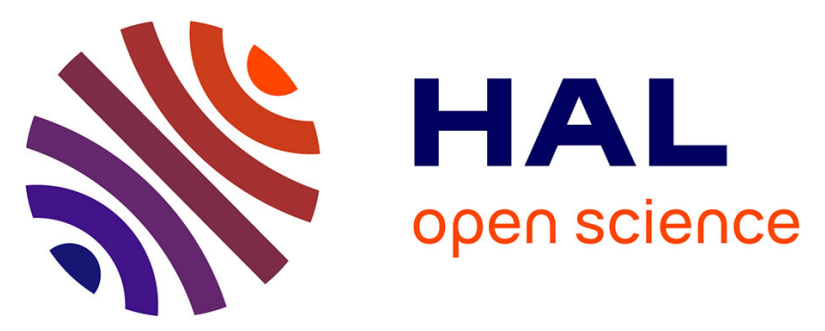

\title{
The DoE method as an efficient tool for modeling the behavior of monocrystalline Si-PV module
}

Fatma Zohra Kessaissia, Abdallah Zegaoui, Mohamed Boutoubat, Hadj

Allouache, Michel Aillerie, Jean-Pierre Charles

\section{- To cite this version:}

Fatma Zohra Kessaissia, Abdallah Zegaoui, Mohamed Boutoubat, Hadj Allouache, Michel Aillerie, et al.. The DoE method as an efficient tool for modeling the behavior of monocrystalline Si-PV module. TMREES18-Spring Meeting "Technologies and Materials for Renewable Energy, Environment and Sustainability", Feb 2018, Beirut, Lebanon. pp.30059 - 30059, 10.1063/1.5039246 . hal-01802890

\section{HAL Id: hal-01802890 \\ https://hal-centralesupelec.archives-ouvertes.fr/hal-01802890}

Submitted on 5 Jun 2018

HAL is a multi-disciplinary open access archive for the deposit and dissemination of scientific research documents, whether they are published or not. The documents may come from teaching and research institutions in France or abroad, or from public or private research centers.
L'archive ouverte pluridisciplinaire HAL, est destinée au dépôt et à la diffusion de documents scientifiques de niveau recherche, publiés ou non, émanant des établissements d'enseignement et de recherche français ou étrangers, des laboratoires publics ou privés. 
The DoE method as an efficient tool for modeling the behavior of monocrystalline Si-PV module

Fatma Zohra Kessaissia, Abdallah Zegaoui, Mohamed Boutoubat, Hadj Allouache, Michel Aillerie, and JeanPierre Charles

Citation: AIP Conference Proceedings 1968, 030059 (2018); doi: 10.1063/1.5039246

View online: https://doi.org/10.1063/1.5039246

View Table of Contents: http://aip.scitation.org/toc/apc/1968/1

Published by the American Institute of Physics 


\title{
The DoE Method as an Efficient Tool for Modeling the Behavior of Monocrystalline Si-PV Module
}

\author{
Fatma Zohra Kessaissia ${ }^{1, a)}$, Abdallah Zegaoui ${ }^{1,2,3, b)}$, Mohamed Boutoubat ${ }^{4}$ \\ Hadj Allouache ${ }^{1}$, Michel Aillerie ${ }^{2,3, c)}$, and Jean-Pierre Charles ${ }^{2,3}$ \\ ${ }^{1}$ LGEER Laboratory, University Hassiba Benbouali of Chlef, BP151, 02000 Chlef, Algeria. \\ ${ }^{2}$ LMOPS, Université de Lorraine, EA-4423, 2 rue E. Belin, 57070 Metz, France. \\ ${ }^{3}$ LMOPS, CentraleSupelec, 2 rue E. Belin, 57070 Metz, France. \\ ${ }^{4}$ LACoSERE Laboratory, Laghouat University, Laghouat, Algeria. \\ a)Corresponding author: kessaissia@gmail.com \\ b)abd.zegaoui@gmail.com \\ c)aillerie@metz.supelec.fr
}

\begin{abstract}
The objective of this paper is to apply the Design of Experiments (DoE) method to study and to obtain a predictive model of any marketed monocrystalline photovoltaic (mc-PV) module. This technique allows us to have a mathematical model that represents the predicted responses depending upon input factors and experimental data. Therefore, the DoE model for characterization and modeling of mc-PV module behavior can be obtained by just performing a set of experimental trials. The DoE model of the mc-PV panel evaluates the predictive maximum power, as a function of irradiation and temperature in a bounded domain of study for inputs. For the mc-PV panel, the predictive model for both one level and two levels were developed taking into account both influences of the main effect and the interactive effects on the considered factors. The DoE method is then implemented by developing a code under Matlab software. The code allows us to simulate, characterize, and validate the predictive model of the mc-PV panel. The calculated results were compared to the experimental data, errors were estimated, and an accurate validation of the predictive models was evaluated by the surface response. Finally, we conclude that the predictive models reproduce the experimental trials and are defined within a good accuracy.
\end{abstract}

\section{INTRODUCTION}

The Design of Experiments (DoE) method can be adapted in order to offer a practical way for studying, modeling, and characterizing the influence of the pertinent parameters involved in the response of PV panels. Indeed, the DoE method has been successfully introduced in industrial systems and research and has built its principles from statistical and mathematical methods [1]. Several domains use the DoE method as those mentioned in Refs [2,3]. Substantially, the DoE method is used to design new industrial products based on both a set of experimental trials and a statistical analysis process [4] in order to optimize the settings of a manufacturing process [5], to improve its performances [6], or to predict and characterize its behavioral model [7-9]. Based on a few experiments in a strict closed study domain of input parameters variation, DoE appears as an alternative method for evaluating the significant factors, correlation between factors and their influence on the response of the system. The method does not require to know the physical model of the studied process. By cons, other physical methods [1012], which can vary only one parameter at a time, are not able to measure the correlation between different input parameters that influence the system response.

To overcome the shortcoming of these physical techniques, the DoE method allows to predict the self-effects as well as the interactions between the different variables involved in the experiment [4,13-14]. Otherwise, to characterize and model any system, the DoE method strongly minimizes the number of experiment trials without influencing accuracy of the response [15]. To model any system, the DoE is concerned with a set of input variables that can modify a specific output variable named by a response of the system. The DoE leads to deduce a 
mathematical model of factorial design of the response as a function of input factors that can vary in a bonded study domain limiting the input parameters variations [16].

In the present work, one can stand out the characterization, the predictive modeling, and the study of the behavior of $\mathrm{m}-\mathrm{PV}$ module by using the DoE technique. We consider in our study, as input parameters of the established predictive model, both variations of the solar irradiation and the PV cell module temperature. For the output responses we consider the short-circuit current, the open-circuit voltage, and the maximum available power of the tested PV module.

\section{FUNDAMENTALS OF DESIGN OF EXPERIMENT METHODS}

\section{Introduction to the DoE Methods}

In the DoE method theory, an experimental domain is geometrically represented by the input factors and output responses as indicated on Fig. 1. Orthogonally factor axes define this experimental domain. Each factor is represented on a graduated axis. To standardize the units, the axis graduations can be with original units or in reduced values [17]. The domain of the study is limited between two important levels: "lower level" and "upper level". The intersection of the factor levels gives an "experimental point". We are focusing in our study on the use of only two input factors; this kind of design is named two-level factorial design and denoted $2^{2}$. All factorial design can be represented by a table when factors exceed two levels or in the other case with a domain of the study that experimental points can be plotted on.

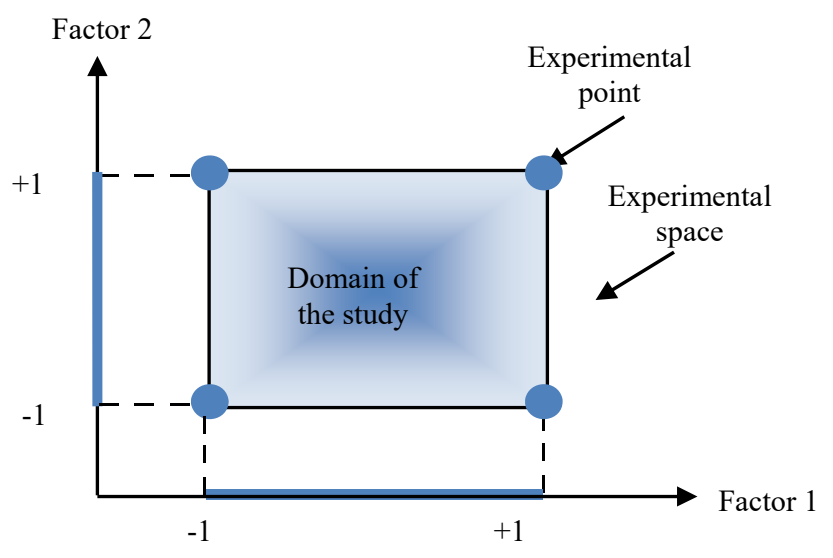

FIGURE 1. The $2^{2}$ experimental factorial design presentation in reduced values.

For graphical representation and unit basis changing, -1 value is attributed to the lower level of the considered factor and +1 value is reserved to its upper level. Two transformations are necessary to obtain the reduced centered values (RCV) named also the coded values: the first one moves the center of measurement and the second one changes the unit of measurement $[17,18]$. The conversion from original values to RCV values and vice versa uses the following formula:

$$
x=\frac{A-A_{0}}{\text { Step }}
$$

where $A_{0}$ is the central value in the coded units $\left(A_{0}=\frac{A_{+1}+A_{-1}}{2}\right)$ and Step is the half of the difference between the upper and the lowest levels $\left(\right.$ step $\left.=\frac{A_{+1}-A_{-1}}{2}\right)$. 


\section{The Predictive Mathematical Model of Response}

The predictive mathematical model that links the response $y$ to the factors $x_{i}$ using the DoE method is established based on the linear regression as follows $[7,8,19,20]$ :

$$
y=a_{0}+\sum_{i=1}^{k} a_{i} x_{i}+\sum_{\substack{i, j=1 \\ i<j}}^{k} a_{i j} x_{i} x_{j}+\sum_{i=1}^{k} a_{i i} x_{i}^{2}
$$

where $x_{i}$ and $x_{j}$ are the levels of the factors $i$ and $j(i, j=1,2, \ldots, k$ : number of factors) are the reduced centered values of factors, they are determined without error.

$a_{0}, a_{i}, a_{i j}, a_{i i}$ denote, respectively, the constant coefficient, the coefficients relative to the principal effect of the factors, the coefficients representing the interactions between several factors, and the coefficients of the seconddegree terms. These coefficients must be calculated from the measurements of trials using our developed code under Matlab.

The matrix form of equation 2 is:

$y=X . a$

with $y$ representing the individual response recorded for the $n$ trials in the study domain, $a$ is the vector of the $n$ corresponding coefficients to be calculated, and $X$ is the design matrix that must be a square matrix.

From Eq. 3, the coefficients of the model can be estimated:

$a=X^{-1} y$

Solving equation 4 using a script developed under Matlab software allows to obtain the needed coefficients.

\section{The One Level Predictive Model}

In the one level predictive model, four trials are enough to have a factorial design $2^{2}$ composed by two factors having two levels each. The $2^{2}$ factorial design is obtained from Eq. 2 when we can stop at the first level term that is based on Eq. 5:

$y=a_{0}+a_{1} x_{1}+a_{2} x_{2}+a_{12} x_{1} x_{2}$

where coefficient $\mathrm{a}_{0}$ is the response to the center of the domain of the study corresponding to $x_{1}=x_{2}=0, x_{1}$ and $x_{2}$ are the measured values of the factors expressed in RCV, the coefficients $a_{12}$ represents the interaction between the two considered factors and $y$ is the measured response values.

\section{The Two Level Predictive Model}

This predictive model considers the second terms of equation 2. Compared to the previous model, this second order predictive model improves strongly the accuracy of response. Named by the two levels model, this model includes the one level model plus the second terms and the errors corresponding to the difference between the data measurement and the calculated response denoted $e$. The two level predictive model is governed by equation 6:

$y=a_{0}+a_{1} x_{1}+a_{2} x_{2}+a_{12} x_{1} x_{2}+a_{11} x_{1}^{2}+a_{22} x_{2}^{2}+e$

Thus, equation 6 in its matrix form is:

$y=X \cdot a+e$ 
The resolution of this system of equations needs an algebraic calculation using the least squares method to estimate both the coefficients $(a)$, and the errors $(e)[21,22]$.

The least squares values $\hat{a}$ of coefficient $a$ are $[14,17,18,23]$ :

$\hat{\mathrm{a}}=\left(X^{\prime} X\right)^{-1} X^{\prime} y$

where: The result of the matrix product $\mathrm{X}^{\prime} \mathrm{X}$ is a square matrix denoted the "information matrix" and if it is invertible one can find $\left(\mathrm{X}^{\prime} \mathrm{X}\right)^{-1}$ named the "dispersion matrix" in the DoE theory.

\section{Validation criterion}

It is necessary to validate the predictive model characterizing the mc-PV module behavior by calculating the error $\left(E_{r}\right)$ corresponding to each experiment $[24,25]$. In this field, the determination coefficient $R^{2}$, ranged between zero and one, is a relevant coefficient to predict the accuracy of the model $[18,26]$. As $\mathrm{R}^{2}$ is closer to the unit, the predictive model is better adjusted.

\section{CHARACTERIZATION OF A PV MODULE WITH THE DOE METHOD}

The behavior of the maximum power available on the mc-PV panel, the short-circuit current, and the opencircuit voltage are modeled according to the environmental variable changes. Figure 2 shows the experimental bench installed at LMOPS Laboratory (at the Universite de Lorraine and CentraleSupelec). The experimental bench is composed of a mc-PV module, a dynamic load used to save the current and the voltage data of PV module, amperemeter, voltage-meter, and scope for plotted I-V characteristics.

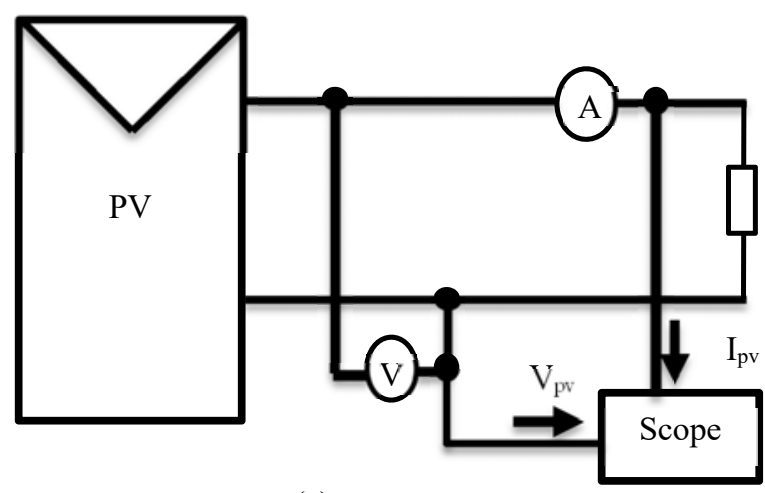

(a)

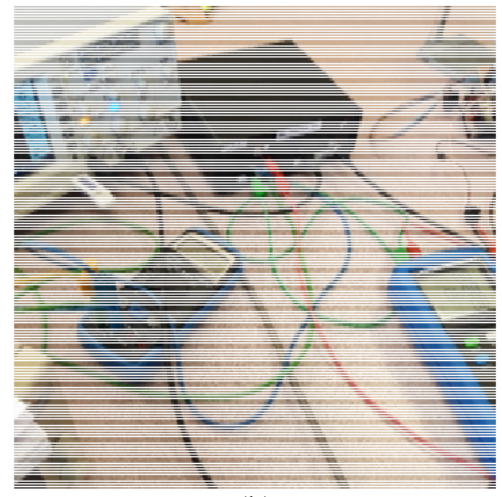

(b)

FIGURE 2. Presentation of schematic experimental bench used for characterizing PV module (a) schematic diagram of experimental bench, (b) experimental bench installed in laboratory.

Table 1 summarizes the datasheet of the considered mc-PV module that is built with 76 cells ( 4 rows of 19 cells), each row in the module is bypassed by a diode.

Table 1. Electrical characteristics from datasheet of PV module under standard test conditions $\left(1000 \mathrm{~W} / \mathrm{m} 2, \mathrm{AM} 1.5\right.$ and $\left.25^{\circ} \mathrm{C}\right)$.

\begin{tabular}{lcccccccc}
\hline PV technology & $\begin{array}{c}\text { Module } \\
\text { reference }\end{array}$ & $\begin{array}{c}\text { Pm } \\
(\mathbf{W})\end{array}$ & $\begin{array}{c}\text { Vpm } \\
(\mathbf{V})\end{array}$ & $\begin{array}{c}\text { Ipm } \\
(\mathbf{A})\end{array}$ & $\begin{array}{c}\text { Voc } \\
(\mathbf{V})\end{array}$ & $\begin{array}{c}\text { Isc } \\
(\mathbf{A})\end{array}$ & Ns & Np \\
\hline Monocrystalline & PS040PR & 40 & 17 & 2.34 & 21 & 2.56 & 38 & 2 \\
\hline
\end{tabular}

The illumination of PV module was provided by an artificial source: the Deltalab $6 \mathrm{~kW}$, as in Ref. [16,27], composed by 6 quartz-halogen bulbs placed at various distances of the experimented PV module and considered as illumination factor. The second considered factor is the temperature of the module, with a permanent controlled ventilation cooling system during experiments. 
The experimental parameters measured are: the illumination $\mathrm{I}\left(\mathrm{W} / \mathrm{m}^{2}\right)$ using a pyranometer, represented by the factor $x_{1}$, the surface temperature $\mathrm{T}\left({ }^{\circ} \mathrm{C}\right)$ of PV panel using infrared thermometer, represented by the factor $x_{2}$, and the short-circuit current $\mathrm{I}_{\mathrm{sc}}$ and open-circuit voltage $\mathrm{V}_{\mathrm{oc}}$ of the panel. The maximum power is obtained from experimental calculation using the formula $P_{m} \simeq 0.72 . V_{o c} . I_{s c}$ as presented in Ref. [28].

Table 2 summarizes the experimental data measurements and the observed responses of experimental design saved after a set of experiments.

Table 2. Experimental design and responses measurements

\begin{tabular}{lccccc}
\hline \multicolumn{3}{c}{ Factors } & \multicolumn{3}{c}{ Responses } \\
\hline $\mathbf{N}^{\circ}$ & $\mathbf{I}(\mathbf{W} / \mathbf{m} \mathbf{2})$ & $\mathbf{T}\left({ }^{\circ} \mathbf{C}\right)$ & Pm $\mathbf{( W )}$ & Isc $(\mathbf{A})$ & Voc $(\mathbf{V})$ \\
\hline $\mathrm{A} 001$ & 571 & 28,9 & 9,93 & 0,706 & 20,1 \\
$\mathrm{~A} 002$ & 571 & 32,6 & 9,92 & 0,712 & 19,9 \\
$\mathrm{~A} 003$ & 571 & 34,7 & 9,87 & 0,716 & 19,7 \\
$\mathrm{~A} 004$ & 823 & 30,5 & 12,83 & 0,894 & 20,5 \\
$\mathrm{~A} 005$ & 823 & 33,2 & 12,99 & 0,914 & 20,3 \\
$\mathrm{~A} 006$ & 823 & 37 & 12,52 & 0,908 & 19,7 \\
$\mathrm{~A} 007$ & 823 & 45,6 & 12,84 & 0,935 & 19,62 \\
$\mathrm{~A} 008$ & 1317 & 34,2 & 18,12 & 1,263 & 20,5 \\
$\mathrm{~A} 009$ & 1317 & 37,1 & 18,03 & 1,269 & 20,3 \\
$\mathrm{~A} 010$ & 1317 & 41,1 & 17,77 & 1,282 & 19,8 \\
$\mathrm{~A} 011$ & 1317 & 43,9 & 17,44 & 1,284 & 19,4 \\
$\mathrm{~A} 012$ & 1781 & 38,1 & 23,28 & 1,638 & 20,3 \\
$\mathrm{~A} 013$ & 1781 & 40,8 & 23,22 & 1,65 & 20,1 \\
$\mathrm{~A} 014$ & 1781 & 48,5 & 22,76 & 1,659 & 19,6 \\
$\mathrm{~A} 015$ & 1781 & 52,5 & 22,55 & 1,678 & 19,2 \\
\hline
\end{tabular}

The application of the DoE method for characterizing the mc-PV module begins by the detailed development of the method for the maximum power response output $\mathrm{P}_{\mathrm{m}}$, and is based on the same procedure, the other output responses are given, i.e. the short-circuit current and the open-circuit voltage responses.

\section{Validation of the One Level Predictive Model}

Firstly, the DoE method is applied to get the one level predictive model, mentioned above by equation 5, using only the four trials: A05, A06, A08, A09, close to the vertices of the domain of the study. Therefore, the RCV of the corresponding factors values denoted $x_{1}$ for illumination and $x_{2}$ for temperature were calculated. Then, the factors $x_{1}$ and $x_{2}$ are replaced by their RCV (Eq. 1) in Eq. 5. The observed response y, which is the maximum power $\mathrm{P}_{\mathrm{m}}$ for the four trials, is given by the following linear system with four equations:

$$
\left\{\begin{array}{c}
a_{0}-a_{1}-a_{2}+a_{12}=12.99 \\
a_{0}+a_{1}-0.4872 a_{2}-0.4872 a_{12}=18.12 \\
a_{0}-a_{1}+0.9487 a_{2}-0.9487 a_{12}=12.52 \\
a_{0}+a_{1}+a_{2}+a_{12}=18.03
\end{array}\right.
$$

This system in its matrix form is:

$$
\left[\begin{array}{cccc}
1.0000 & -1.0000 & -1.0000 & 1.0000 \\
1.0000 & 1.0000 & -0.4872 & -0.4872 \\
1.0000 & -1.0000 & 0.9487 & -0.9487 \\
1.0000 & 1.0000 & 1.0000 & 1.0000
\end{array}\right]\left[\begin{array}{l}
a_{0} \\
a_{1} \\
a_{2} \\
a_{12}
\end{array}\right]=\left[\begin{array}{l}
12.99 \\
18.12 \\
12.52 \\
18.03
\end{array}\right]
$$

Resolution of the linear system in eq. 10 allows to obtain the calculated coefficients as indicated in Eq. 4: 


$$
\left[\begin{array}{l}
a_{0} \\
a_{1} \\
a_{2} \\
a_{12}
\end{array}\right]=\left[\begin{array}{c}
15.4197 \\
2.6709 \\
-0.1509 \\
0.0903
\end{array}\right]
$$

By substituting these coefficients in Eq.5, we obtain the one level predictive model of the maximum power response:

$$
P_{m}=15.4197+2.6709 x_{1}-0.1509 x_{2}+0.0903 x_{1} x_{2}
$$

The same procedure to predict the maximum power model is performed to model the short-circuit current $I_{s c}$ and the open circuit voltage $V_{o c}$ :

$$
\begin{aligned}
& V_{o c}=20.2133+0.2212 x_{1}-0.2212 x_{2}+0.0867 x_{1} x_{2} \\
& I_{s c}=1.0879+0.177 x_{1}+0.0005 x_{2}+0.0036 x_{1} x_{2}
\end{aligned}
$$

Thanks to the DoE method, Eq. 12, 13 and 14 offer the possibility to find the correct response values for any factor in its domain of study without performing experiments for all the points.

\section{Validation of the Two Level Predictive Model}

Secondly, the DoE method improves the accuracy of the model by considering the second terms coefficients even so it requires more experimental trials than the one level predictive model. Using the same procedure as in the first part, by replacing the factors $x_{1}$ and $x_{2}$ by their RCV calculated from table 2, we obtain the system of equations:

$$
\left\{\begin{array}{c}
a_{0}-a_{1}-a_{2}+a_{12}+a_{11}+a_{22}+e_{1}=9.93 \\
a_{0}-a_{1}-0.6864 a_{2}+0.6864 a_{12}+a_{11}+0.4712 a_{22}+e_{2}=9.92 \\
\cdots \\
\cdots \\
a_{0}+a_{1}+a_{2}+a_{12}+a_{11}+a_{22}+e_{15}=22.55
\end{array}\right.
$$

This system requires fifteen trials; each trial corresponds to an equation adding an error which is the difference between the measured response and its calculated value; mentioned $e_{1}$. Therefore, this system possesses 15 error values and 6 coefficients to be calculated. In total there are 21 unknowns and, with 15 equations, this system cannot be solved by the Eq.3, but it can be resolved by the use of the least square method indicated by Eq.7. The model coefficients are calculated using the Eq.8: 


$\left[\begin{array}{cccccc}1.0000 & -1.0000 & -1.0000 & 1.0000 & 1.0000 & 1.0000 \\ 1.0000 & -1.0000 & -0.6864 & 0.6864 & 1.0000 & 0.4712 \\ 1.0000 & -1.0000 & -0.5085 & 0.5085 & 1.0000 & 0.2585 \\ 1.0000 & -0.5840 & -0.8644 & 0.5085 & 1.0000 & 0.7472 \\ 1.0000 & -0.5840 & -0.6356 & 0.3712 & 0.3411 & 0.4040 \\ 1.0000 & -0.5840 & -0.3136 & -0.1831 & 0.3411 & 0.0983 \\ 1.0000 & -0.5840 & 0.4153 & -0.2425 & 0.3411 & 0.1724 \\ 1.0000 & 0.2320 & -0.5508 & -0.1278 & 0.0538 & 0.3034 \\ 1.0000 & 0.2320 & -0.3051 & -0.0708 & 0.0538 & 0.0931 \\ 1.0000 & 0.2320 & 0.0339 & 0.0079 & 0.0538 & 0.0011 \\ 1.0000 & 0.2320 & 0.2712 & 0.0629 & 0.0538 & 0.0735 \\ 1.0000 & 1.0000 & -0.2203 & -0.2203 & 1.0000 & 0.0485 \\ 1.0000 & 1.0000 & 0.0085 & 0.0085 & 1.0000 & 0.0001 \\ 1.0000 & 1.0000 & 0.6610 & 0.6610 & 1.0000 & 0.4369 \\ 1.0000 & 1.0000 & 1.0000 & 1.0000 & 1.0000 & 1.0000\end{array}\right]\left[\begin{array}{l}a_{0} \\ a_{1} \\ a_{2} \\ a_{12} \\ a_{11} \\ a_{22}\end{array}\right]+\left[\begin{array}{c}e_{1} \\ e_{2} \\ e_{3} \\ e_{4} \\ e_{5} \\ e_{6} \\ e_{7} \\ e_{8} \\ e_{9} \\ e_{10} \\ e_{11} \\ e_{12} \\ e_{13} \\ e_{14} \\ e_{15} \\ e_{16}\end{array}\right]=\left[\begin{array}{c}9.93 \\ 9.92 \\ 9.87 \\ 12.83 \\ 12.99 \\ 12.52 \\ 12.84 \\ 18.12 \\ 18.03 \\ 17.77 \\ 17.44 \\ 23.28 \\ 23.22 \\ 22.76 \\ 22.55\end{array}\right]$

The developed code under Matlab software applied for eq.16 gives the following coefficients:

$$
\hat{a}=\left[\begin{array}{c}
16.2608 \\
6.5152 \\
-0.2553 \\
-0.8218 \\
0.3399 \\
0.5431
\end{array}\right]
$$

The substitution of these coefficients in Eq. 6 leads to the calculated response of the maximum power of the predictive model, the short-circuit current and the open-circuit voltage models respectively:

$$
\begin{aligned}
& P_{m}=16.2608+6.5152 x_{1}-0.2553 x_{2}-0.8218 x_{1} x_{2}+0.3399 x_{1}^{2}+0.5431 x_{2}^{2} \\
& V_{o c}=19.7808+0.2927 x_{1}-0.7768 x_{2}-0.6136 x_{1} x_{2}-0.0043 x_{1}^{2}+0.593 x_{2}^{2} \\
& I_{s c}=1.1748+0.4524 x_{1}+0.0309 x_{2}-0.0107 x_{1} x_{2}+0.0159 x_{1}^{2}+0.0126 x_{2}^{2}
\end{aligned}
$$

These predictive models help to detect the significant factor and to inform about the direction of response variation. As for the previous three predictive models, the coefficient $a_{l}$ corresponding to illumination presents a positive sign, its means that the maximum power, the open-circuit voltage and the short-circuit current change in the same direction as the illumination changes. Then, the $P_{m}$ and $I_{s c}$ models are strongly depend on the coefficient $a_{l}$, but the $V_{o c}$ model varies with coefficient $a_{2}$ corresponding to temperature changes greater than the illumination, which confirm the practical behavior of mc-PV panel [29].

\section{RESULTS AND DISCUSSION}

Table 3 summarizes the results of the two predictive models previously detailed. The maximum power response given by the one level predictive model of Eq. 12, provided high error values, that explains an excluded experimental point characterized by an error superior to $10 \%$. The two level predictive model mentioned by Eq. 18, gives a small difference between the measured and calculated values of maximum power, as indicated by error values smaller than that of the first model.

For the one level predictive model established from four trials, the coefficient $\mathrm{R}^{2}$ is equal to one. Nevertheless, with only four trials, the whole phenomenon cannot be fully understood. The two level predictive model gives a determination coefficient $\mathrm{R}^{2}=0.9995$, close to the unit, that means the high dependence of the observed and estimated maximum power responses. 
Table 3. Results of the calculated maximum power response and their errors

\begin{tabular}{clcccc}
\hline Trials & \multicolumn{5}{c}{ Maximum power value (VA) } \\
\cline { 2 - 6 } & Experimental & Mod. 1 /Eq. 12 & Er (\%) & Mod. 2 /Eq. 18 & Er (\%) \\
\hline A001 & 9,93 & 11.09 & -10.46 & 10.06 & 1.27 \\
A002 & 9,92 & 10.46 & -5.16 & 9.95 & 0.32 \\
A003 & 9,87 & 10.1 & -2.28 & 9.94 & 0.67 \\
A004 & 12,83 & 13.32 & -3.68 & 12.78 & -0.38 \\
A005 & 12,99 & 12.99 & 0 & 12.65 & -2.6 \\
A006 & 12,52 & 12.52 & 0 & 12.55 & 0.23 \\
A007 & 12,84 & 11.46 & 12.04 & 12.76 & -0.63 \\
A008 & 18,12 & 18.12 & 0 & 18.2 & 0.42 \\
A009 & 18,03 & 18.03 & 0 & 17.98 & -0.29 \\
A010 & 17,77 & 17.91 & -0.78 & 17.78 & 0.06 \\
A011 & 17,44 & 17.82 & -2.13 & 17.71 & 1.57 \\
A012 & 23,28 & 23.27 & 0.04 & 23.38 & 0.45 \\
A013 & 23,22 & 23.42 & -0.85 & 23.11 & -0.45 \\
A014 & 22,76 & 23.86 & -4.61 & 22.64 & -0.53 \\
A015 & 22,55 & 24.08 & -6.35 & 22.58 & 0.12 \\
\hline
\end{tabular}

(a) Pm surface response

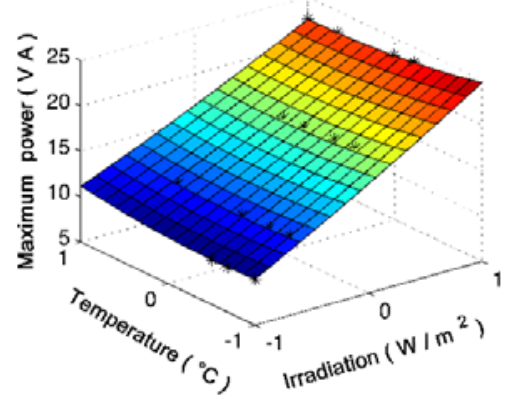

(d) $\mathbf{P m}$

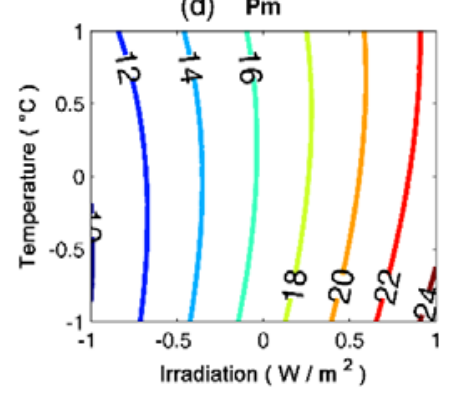

(b) Voc surface response

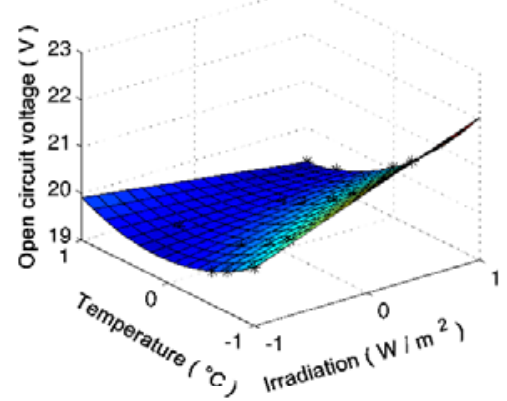

(e) Voc

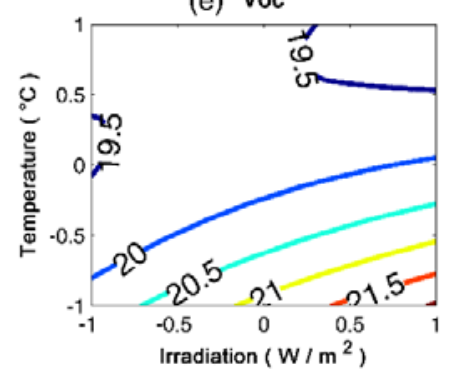

(c) Isc surface response

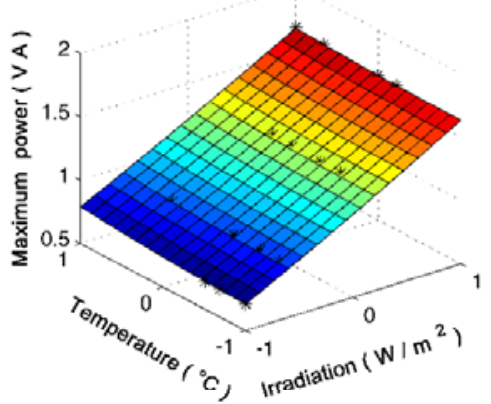

(f) Isc

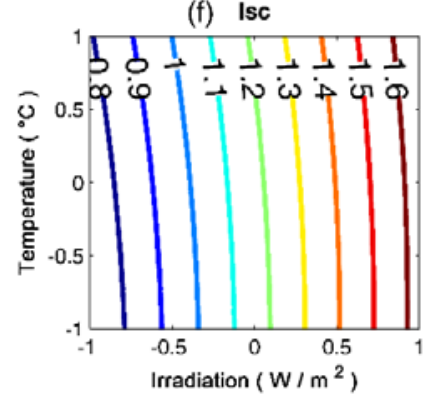

FIGURE 3. Surface responses (a), (b), (c) for the maximum power, the open-circuit voltage and short-circuit current and their contour curves (d), (e), (f), respectively.

The surface response in the DoE method is another way to represent the response variation in the considered predictive models. Figures 3 shows the surface response of the maximum power, the open-circuit voltage and the short-circuit current as functions of the temperature and the irradiation for the two level predictive model. From this figure, one can notice that the maximum power calculated by the DoE method is close to that measured given by the experiment trials. Power changes in the same direction of the irradiation changes and inversely with temperature changes. The influence of the two factors in the same response can be obtained by a simple clicking on the considered point on the curves. The same conclusion can be performed on the contour curves graphical representation. 


\section{CONCLUSION}

The DoE method was implemented and tested for characterizing and modeling the behavior of a monocrystalline photovoltaic module. The DoE method is proposed to enhance the system study and to save time. It does not require physical details of the studied system but only needs a few trials of experiments by varying inputs parameters and measuring concerned output factors for each case. The main aim of this work is to model the behavior of monocrystalline PV module and to validate the results by experimentation. In order to perform the DoE modeling of our process, only a set of fifteen experimental trials is enough to take into account all pertinent input and output variables. The influence of both input factors: irradiations solar and temperature on the different outputs response factors (maximum power, short-circuit current and open-voltage) are studied. One can notice the greater dependence of the maximum power and short-circuit current responses with the illumination than with the temperature, whereas the open-circuit voltage response is inversely related to the temperature variation. The correlation between the two input factors for output influence is carried out. The results show a strong correspondence between the calculated form of the predictive model. Moreover the measured responses and the difference between both prove that the DoE method is an efficient tool, well adapted to model photovoltaic modules within a good accuracy.

\section{REFERENCES}

1. W. Tinsson, Plans d'expériences : constructions et analyses statistiques (Ed. Springer, Berlin, 2010).

2. F. Gillon, "Modélisation et optimisation par les plans d'expériences d'un moteur à commutations électroniques", $\mathrm{PhD}$ thesis, Université des sciences et technologies-Lille (1997).

3. P. Dagnelie, Principes d'expérimentations planification des expériences et analyse de leurs résultats (Presses agronomiques de Gembloux, Belgique 2012).

4. M. Michaelis, C.S. Leopold, "A measurement system analysis with design of experiments: Investigation of the adhesion performance of a pressure sensitive adhesive with the probe tack test" International Journal of Pharmaceutics, 448-456 (2015).

5. I. Saha, N. Jain, S. Kumar, "Using design of experiments approach to optimize custom emitter clean process used in PV”, Energy Procedia, 8, 688-693 (2011).

6. J.A.B. Montevechi, A.F. De Pinho, F. Leal, F.A.S. Marins, "Application of design of experiments on the simulation of a process in an automotive industry", Proc. of the Winter Simulation Conf., 1601-1609 (2007).

7. F. Hannane, H. El Mossaoui, T.V. Nguyen, P. Petit, M. Aillerie, J.P. Charles, "Forecasting the PV panel operating conditions using the Design of experiments method" Energy Procedia, 36, 479-487 (2013).

8. J.P. Charles, F. Hannane, H. El Mossaoui, A. Zegaoui, T.V. Nguyen, P. Petit and M. Aillerie, "Faulty PV panel identification using the Design of experiments (DoE) ", International Journal of Electrical Power \& Energy Systems, 57, 31-38 (2014).

9. J. Goupy, La méthode des plans d'expériences Optimisation du choix des essais et de l'interprétation des résultats (Ed. Dunod, Paris, 1988).

10. P. Moçotéguy, B. Ludwing, N.Y. Steiner, "Application of current steps and design of experiments methodology to the detection of water management faults in a proton exchange membrane fuel cell stack", Journal of Power Sources, 303, 126-136 (2016).

11. J.L. Goupy, Methods for experimental design Principles and applications for physicists and chemists (in Data handing in science and technology, Paris, 1993).

12. A. Zegaoui, P. Petit, M. Aillerie, J.P. Sawicki, A.W. Belarbi, M.D. Krachai, J.P. Charles, "Photovoltaic Cell/Panel/Array Characterizations and Modeling Considering both Reverse and Direct Modes", Energy Procedia, 6, 695-703 (2011).

13. F. Elkhalil, "Supervision, économie et impact sur l'environnement d'un système d'énergie électrique associé à une centrale photovoltaïque", $\mathrm{PhD}$ thesis, Institut des sciences et technologies, Paris (2011).

14. A. Guenounou, A. Malek, M. Aillerie, "Comparative performance of PV panels of different technologies over one year of exposure: Application to a coastal Mediterranean region of Algeria", Energy Conversion and Management, 114, 356-363 (2016).

15. N. Lemonakis, A.L. Skaltsounis, A. Tsarbopoulos, E. Gikas, "Optimization of parameters affecting signal intensity in an LTQ-orbitrap in negative ion mode: a design of experiments", Talanta, 147, $402-409$ (2016). 
16. J.P. Charles, M. Aillerie, P. Petit, F. Hannane, H. El Mossaoui, "Warning of accidental shadowing of a PV generator in operation analyzed with the DoE method", Solar Energy, 122, 455-463 (2015).

17. J. Goupy, L. Creighton, Introduction to design of experiments with JMP Examples (Ed. SAS, USA, 2007).

18. J. Goupy, Pratiquer les plans d'expériences (Ed. Dunod, Paris ; 2005).

19. J. Goupy, Introduction aux plans d'expériences avec applications (Ed. Dunod, Paris, 2013).

20. F. Rabier, "Modélisation par la méthode des plans d'expériences du comportement dynamique d'un module IGBT utilisé en traction ferroviaire", PhD thesis, Institut nationale polytechnique-Toulouse (2007).

21. K.B. Petersen, M.S. Pedersen, in The matrix cookbook (Denmark, 2012).

22. G. Saporta, Probabilités et analyse des données et statistiques (Ed. Technip, Paris, 2006).

23. R. Linder, Les plans d'expériences Un outil indispensable à l'expérimentateur (Presses de l'école nationale des ponts et chaussées, Paris, 2005).

24. F. Rouessac, E. Rouessac, D. Cruché, C. Duverger-Arfuso, D. Martel, Analyse chimique Méthodes et techniques instrumentales modernes (Ed. Dunod, 2009).

25. F.Z. Kessaissia, A. Zegaoui, A. Hadj Arab, L. Loukarfi, M. Aillerie, "Comparison of two PV modules technologies using analytical and experimental methods", Energy Procedia, 74, 389-397 (2015).

26. J. Faucher, "Les plans d'expériences pour le réglage de commandes à base de logique floue", PhD thesis, Institut national polytechnique-Toulouse, (2006).

27. P. Petit, "Optimisation du transfert d'énergie dans les systèmes photovoltaïques", $\mathrm{PhD}$ thesis, Université de Lorraine-France, (2011).

28. A. Zegaoui, M. Aillerie, P. Petit, J.P. Sawicki, J.P. Charles, A.W. Belarbi, "Dynamic behaviour of PV generator trackers under irradiation and temperature changes”, Solar Energy, 85(11), 2953-2964 (2011).

29. M. Chegaar, A. Hamzaoui, A. Namoda, P. Petit, M. Aillerie, A. Herguth, "Effect of Illumination Intensity on Solar Cells Parameters" Energy Procedia, 36, $722-729$ (2013). 